\title{
Silencing of Long Non-Coding RNA Inhibits Proliferation and Invasion of Non-Small Cell Lung Cancer
}

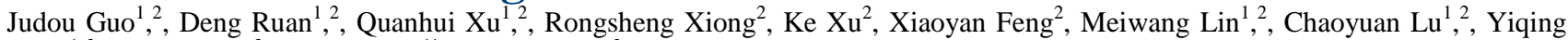
Deng $^{1},{ }^{2}$, Yuan Zhang ${ }^{3}$, Jianfei Song ${ }^{4 *}$, Zhenzong $\mathrm{Du}^{2}$

\author{
${ }^{1}$ College of Graduate, Guilin Medical University, Guilin, Guangxi Zhuang 541001, P.R. China \\ ${ }^{2}$ Department of Thoracic Surgery, Nanxishan Hospital of Guangxi Zhuang Autonomous Region, Guilin, Guangxi Zhuang 541002, P.R. China \\ ${ }^{3}$ College of Pharmacy of Guilin Medical University, Guilin, Guangxi Zhuang 541004, P.R. China \\ ${ }^{4}$ Department of Thoracic and Cardiovascular Surgery, The Second Affiliated Hospital of Guilin Medical University, Guilin, Guangxi Zhuang 541100, \\ P.R. China
}

DOI:10.36347/sasim.2021.v07i01.006 | Received: 14.01.2021 | Accepted: 25.01.2021| Published: 30.01 .2021

*Corresponding author: Professor Jianfei Song

Abstract

Background and Aim: Non-small cell lung cancer (NSCLC) is one of the most common clinical malignant tumors. According to the World Health Organization (WHO), NSCLC has become the most common malignant tumor with the highest morbidity and mortality. This paper aims to investigate the mechanism of LncRNAG058036 in NSCLC. Methods: LncRNAG058036 was screened out by bioinformatics analysis, and the expression of G058036 in NSCLC tissues and adjacent non-cancer tissues was compared by quantitative real-time polymerase chain reaction. Survival analysis of Patients with G058036 in NSCLC.G058036shRNA was used to transfection NSCLC A549 and H838, and proliferation, invasion and apoptosis were observed by comparing the experimental group with the control group. Results: LncRNAG058036 was significantly increased in NSCLC tissues, and G058036 knockout could significantly inhibit the proliferation, invasion and apoptosis of A549 and H838 cells. Conclusion: LncRNAG058036 is upregulated in NSCLC and may be a potential target for diagnosis, treatment and prognosis of NSCLC.

Keywords: Silencing of Long Non-Coding RNA Proliferation and Invasion Cell Lung Cancer.

Copyright $\odot 2021$ The Author(s): This is an open-access article distributed under the terms of the Creative Commons Attribution 4.0 International License (CC BY-NC 4.0) which permits unrestricted use, distribution, and reproduction in any medium for non-commercial use provided the original author and source are credited.

\section{INTRODUCTION}

The incidence and mortality of lung cancer are rising rapidly in China [1, 2]. Among them, Non-small cell lung cancer (NSCLC) accounts for about 80\% $85 \%$ of the total lung cancer, with rapid disease development, rapid metastasis and high recurrence rate [3]. Most patients are found to have advanced stage with poor prognosis. The recurrence rate of NSCLC patients who received early treatment was higher. More than $70 \%$ of the patients were found to have local invasion or distant metastasis, so they could not be operated $[2,4]$.Therefore, it is of great significance to explore new therapeutic models and therapeutic targets for improving the therapeutic effect and prolonging the survival time of patients with NSCLC.

Long non-coding RNA (lnc RNAs) is a class of RNA molecules with transcripts between 200nt$100 \mathrm{~KB}$ in length that does not or rarely code for proteins[5]. It has been found that lnc RNAs are abnormally expressed in a variety of tumors, and certain ultra-conservative elements in lnc RNAs are widely expressed in human tumor cells[6]. LncRNAs can participate in epigenetic modification, transcriptional regulation, RNA editing, protein translation and modification and other important cellular molecular events, and play a key role in tumor proliferation, metastasis, dry maintenance, drug resistance and other processes [7].

LncRNAG058036 is a newly identified LncRNA through bioinformatics analysis, and its role in the occurrence and development of cancer has not been studied by relevant researchers at present. In this study, we found that LncRNAG058036 was up-regulated in NSCLC tissues, and the deletion of LncRNAG058036 could inhibit the proliferation and invasion of NSCLC cells. 


\section{MATERIALS AND METHODS}

\section{Patients and tissue samples}

We included 30 pairs of non-small cell lung cancer tissues and adjacent non-tumor tissues hospitalized at Nanxishan Hospital, Guangxi Zhuang Autonomous Region, from June 2014 to May 2019.Immediately after surgery, tissue samples are stored in liquid nitrogen until further analysis.Patients with a history of radiation and/or chemotherapy were excluded. This study was approved by the Ethics Committee of Nanxishan Hospital in Guangxi Zhuang Autonomous Region, and all participants signed informed consent.

\section{Cell lines and cell culture}

Human non-small cell lung cancer cell lines H838 and A549 were purchased from ATCC Company. They were digested with $0.5 \%$ EDTA trypsin, washed with Hanks solution for 3 times, and screened with 100 mesh cells to prepare single cell suspension. H838 cell line was cultured in RPMI-1640 culture medium containing $10 \% \mathrm{FBS}$ and $1 \%$ double antibody at $37{ }^{\circ} \mathrm{C}$, $5 \% \mathrm{CO} 2$ and saturated humidity, and was passaged to logarithmic growth stage for practical test. A549 cell line was cultured in DMEM medium containing $10 \%$ FBS, $2 \mathrm{mM} / \mathrm{L}$ L-glutamine and $1 \%$ double antibody at $37^{\circ} \mathrm{C}, 5 \% \mathrm{CO} 2$ and saturated humidity, and subcultured to logarithmic growth stage for experiment.

\section{RNA extraction and qRT-PCR}

Collect the cells after the intervention treatment by centrifugation in a $1.5 \mathrm{ml}$ centrifuge tube, wash them twice with PBS, add $1 \mathrm{ml}$ TRIzol reagent, blow with a pipette until the cells are completely lysed, place them on ice for $5 \mathrm{~min}$, then add $0.3 \mathrm{ml}$ of precooled chloroform, shake and mix evenly, and then stand at room temperature for $5 \mathrm{~min} ; 12,000 \mathrm{~g}$, centrifuge at $4^{\circ} \mathrm{C}$ for $15 \mathrm{~min}$; $0.8 \mathrm{ml}$ of supernatant was taken and transferred to a $1.5 \mathrm{ml}$ centrifuge tube. Add precooled isopropanol, vortex and mix, and place on ice for $10 \mathrm{~min}$; Centrifuge at $4^{\circ} \mathrm{C}$ and $10,000 \mathrm{~g}$ for $10 \mathrm{~min}$; Discard the supernatant, add $10 \mathrm{ml}$ of $75 \%$ precooled ethanol and mix well; Centrifuge at $4{ }^{\circ} \mathrm{C}$ and 7,000 $\mathrm{g}$ for $5 \mathrm{~min}$. The supernatant was discarded and dried at room temperature for $5 \mathrm{~min}$; . DEPC was dissolved in water and stored at $-80^{\circ} \mathrm{C}$. The quality of RNA was detected by electrophoresis and ultraviolet spectrophotometer. With $2 \mu \mathrm{g}$ of total RNA as template, the reverse transcription reaction system was prepared according to the instructions of BestarTM qPCR RT Kit. the first strand of cDNA was synthesized, and the reverse transcribed cDNA was stored at $-20^{\circ} \mathrm{C}$. The reaction system of Real-time PCR amplification is $20 \mu$ (1 DBI bestar sybr green qpcr master mix), and the PCR reaction conditions are $95^{\circ} \mathrm{C}$ for $2 \mathrm{~min}, 94^{\circ} \mathrm{C}$ for $20 \mathrm{~s}$, $58^{\circ} \mathrm{C}$ for $20 \mathrm{~s}$, and 40 cycles. Melting curve analysis: temperature $65^{\circ} \mathrm{C} \sim 95^{\circ} \mathrm{C}$. Each sample was repeated 3 times. Primers were designed with reference to software design and literature reports. The fluorescence quantitative PCR experiment was carried out with
Agilent Stratagene fluorescence quantitative PCR instrument Mx3000P, and the data were collected. Data were processed according to $2-\Delta \Delta \Delta \mathrm{CT}$ method. Among them, ${ }^{\Delta} \mathrm{Ct}=$ the mean standard deviation of (target gene $\mathrm{Ct}$ - internal reference $\mathrm{Ct}$ ); ${ }^{\Delta \Delta} \mathrm{Ct}=$ the mean value standard deviation of (target gene ${ }^{\Delta} \mathrm{Ct}$ in the sample to be tested-target gene $\Delta \mathrm{CT}$ in the reference sample); Relative sample initial template amount $=(2-\Delta \Delta \Delta \mathrm{CT})$ mean standard deviation.

\section{Cell Transfection}

Interference lentivirus is intended to be purchased by Suzhou Jima Company, One day before the experiment, $1 \times 10^{4}$ cells/well, $100 \mu \mathrm{L}$ complete medium was added and cultured at $37^{\circ} \mathrm{C}$ with $5 \% \mathrm{CO} 2.10 \mathrm{~L} 1 \times 10^{8} \mathrm{TU} / \mathrm{mL}$ virus (pre-extracted from $80^{\circ} \mathrm{C}$ and melted on ice) $+40 \mathrm{~L}$ complete culture medium + final concentration $5 \mathrm{~g} / \mathrm{ml}$ polybrene $(\mathrm{MOI}=100)$. The venom was added to the 96 -well plate of inoculated cells and cultured overnight at $37^{\circ} \mathrm{C}$ with $5 \% \mathrm{CO} 2$.After $24 \mathrm{~h}$, the infected cells were removed: the cells were collected into a centrifuge tube, $800 \mathrm{rpm}$, and the old medium was discarded for $5 \mathrm{~min} .100 \mu \mathrm{L}$ fresh and complete medium was added. The cells were resuspended, cultured at $37^{\circ} \mathrm{C}$ and $5 \% \mathrm{CO} 2$, and the cell transfection efficiency was observed under a fluorescence microscope $48 \mathrm{~h}$ later. After 48 hours of viral infection, the cells were cultured in a complete medium containing $1 \mathrm{~g} / \mathrm{ml}$ puromycin, and after sufficient cell growth, the cells were transferred, $60 \mathrm{~mm}$ petri dish, expanded culture. The cells were cultured in complete medium containing $5 \mathrm{~g} / \mathrm{ml}$ puromycin. The culture medium containing a large number of dead cells was replaced with a complete medium containing 5 $\mathrm{g} / \mathrm{ml}$ puromycin every other day until the resistant community could be identified. The resistant cells were observed under fluorescence microscope with Luciferin substrate. After the resistant cells were overgrown, the culture was continued to expand until the required number of cells.

\section{Transwell Assay}

After the cells were digested and centrifugated, the concentration of each cell was adjusted to $2 \times 10^{5} / \mathrm{ml}$. The cell suspension of $100 \mu \mathrm{L}$ was added into the Transwell chamber, that is, $2 \times 10^{4}$ cells per well. Then $700 \mu \mathrm{L}$ of complete medium containing $10 \%$ FBS serum was added to the chamber, and the cells were placed in an incubator with $5 \% \mathrm{CO} 2$ and $37^{\circ} \mathrm{C}$ for routine culture for 48 hours. Take out the small room, wipe gently with cotton swabs cells of the upper chamber, PBS washing chamber 3 times, use 20 min $4 \%$ paraformaldehyde fixed small room, take out the small room, use small PBS washing room 3 times, the small room in the equipped with liquid crystal violet dye in the dye VAT dyeing $5 \sim 10 \mathrm{~min}$, remove and rinse water dyeing liquid, USES a scalpel to remove small room, dry, use neutral resin sealing piece.OLYMPUSCX41 normal microscope was used to observe and photograph the cells in 6 fields and IPP software was used for cell 
counting. The experiment was repeated independently for 3 times.

\section{Colony Formation Assays}

The cultured cells were digested by trypsin, and the cells were resuspended by $1 \mathrm{ml}$ medium, diluted into $1 \times 10^{3} / \mathrm{ml}$ inoculation and $96-$ well plate. The inoculation was performed by $50 \mu \mathrm{L}$ inoculation, $100 \mu \mathrm{L}$ inoculation or 100 cells/well, and $200 \mu \mathrm{L}$ inoculation or 200 cells/well. After inoculation, culture medium was added to each well to reach $300 \mu \mathrm{L} /$ well. The culture plates were shaken horizontally to the left and right, although the distribution of cells in the pores was uniform. After 7 days of culture, each well culture medium was sucked and rinsed with PBS twice. After fixation, $200 \mu \mathrm{L}$ crystal violet staining solution was added to each well to fully cover the bottom of the hole. After 20 minutes, 96 Wells were placed under tap water for washing, pay attention to slow water flow, and then dried, and the colony number was calculated

\section{EDU Assays}

Cell slides were prepared according to experimental groups, cell immobilized, and EDU detection was performed: $100 \mu \mathrm{L} 1 \times$ Apollo staining solution was added to each well, and incubated at room temperature for 30 minutes in the dark. $100 \mu \mathrm{L}$ PBS was added to each well to wash once, and the precipitated cells were discarded. DNA staining: The supernatant was discarded, and $100 \mu \mathrm{L} 1 \times$ Hoechst 33342 reaction solution was added to each well. The reaction solution was incubated at room temperature for 10-30 minutes in dark, and $100 \mu \mathrm{L}$ osmotic agent $(0.5 \%$ TRitonX-100
PBS) was added to each well for several times to elute Hoechst33342.

\section{TUNEL}

TUNEL test solution: TdT enzyme $10 \mu \mathrm{L}+$ fluorescence test solution $24 \mu \mathrm{L}+\mathrm{TUNEL}$ test solution $250 \mu \mathrm{L}$;Adherent cells were washed twice with PBS, $50 \mu \mathrm{L}$ of TUNEL detection solution was added into the sample, incubated at $37^{\circ} \mathrm{C}$ in dark for 60 minutes, washed with PBS for 3 times, and then the tablets were quenched and sealed with fluorescence microscope for observation. The excitation wavelength range that can be used is $450 \mathrm{~nm}$, and the emission wavelength range is 515-565nm (green fluorescence).

\section{STATISTICAL ANALYSIS}

The results were input into the computer, a database was established, and SPSS26.0 statistical software was used for analysis, rank sum test was used for grade data, chi-square test was used for classification data comparison, chi-square test was used for comparison of the two-sample mean, one-way ANOVA was used for comparison of the multi-group mean, LSD test was used for pair-wise comparison, and was considered statistically significant. The dose-effect curves were drawn and fitted using Excel 2010, SPSS 20.0 and Graphpad Prism 8.0.

\section{RESULTS}

1.G058036 upregulation and its diagnostic significance in non-small cell lung cancer. 


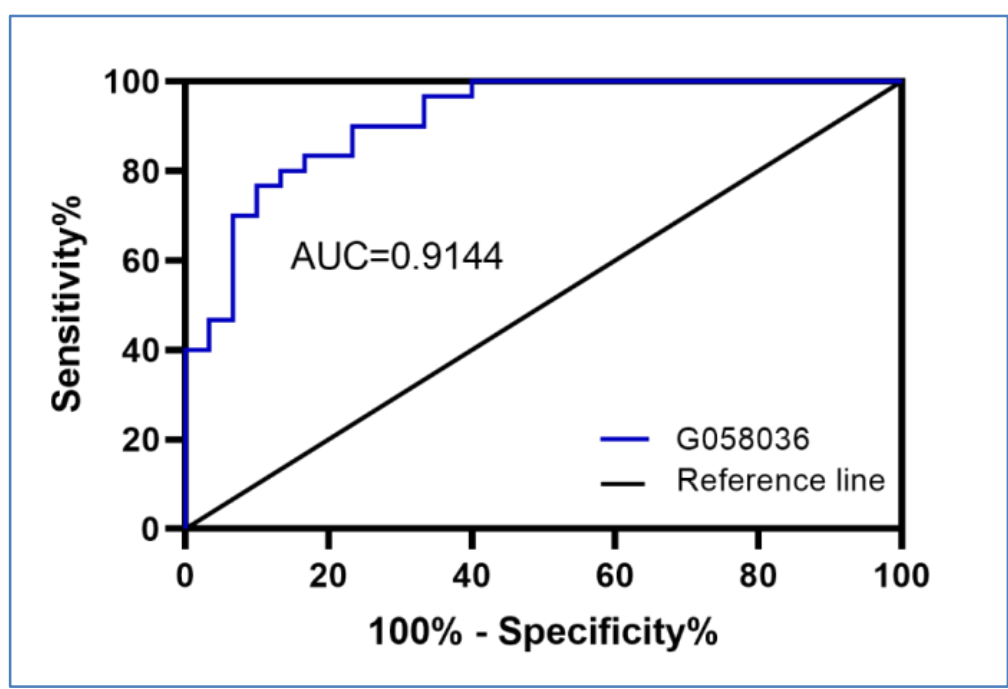

Fig-1: G058036 is upregulated in non-small cell lung cancer. (a) G058036 expression in non-small cell lung cancer tumor tissues and adjacent tissues was compared by quantitative reverse transcription polymerase chain reaction.(b) Results of receiver operating characteristics analysis. $* * * * P<0.0001$

We compared the expression of G058036 in non-small cell lung cancer tumor specimens with adjacent non-tumor specimens by quantitative reverse transcription polymerase chain reaction.As shown in Figure 1, G058036 was significantly increased in NSCLC tumor samples compared with adjacent nontumor tissue samples (Figure 1(a), $P<0.0001$ ). The area under the curve (AUC) of G058036 was 0.9144 (95\% confidence interval $0.8163,0.9423$ ), indicating that G058036 is a highly sensitive diagnostic marker that can distinguish tumor tissue from normal tissue (Figure 1(b) $p=0.9144$ ).The expression of $\mathrm{G} 058036$ is positively correlated with tumor size $(p<0.01)$, degree of differentiation $(\mathrm{p}<0.01)$, and whether it has metastasis $(p<0.05)$ (Table 1).

Table-1: Clinical information of the patient

\begin{tabular}{cccc|}
\hline & & & \\
& & & \\
& & & \\
\hline & G058036 & G058036 & P value \\
High(n=36) & Low(n=24) & \\
\hline Gender & & & 0.8315 \\
Male & 20 & 14 & \\
Female & 16 & 10 & \\
Age (years) & & & 0.5982 \\
$<60$ & 19 & 11 & \\
$\geqq 60$ & 17 & 13 & \\
Tumor size (cm) & & & $0.0075^{* *}$ \\
$<3$ & 10 & 15 & \\
$\geqq 3$ & 26 & 9 & \\
Differentiation & & & $0.0084^{* *}$ \\
Well-intermediate & 13 & 17 & \\
Poor & 23 & 7 & \\
Metastasis & & & $0.0110^{*}$ \\
No & 15 & 18 & \\
Yes & 21 & 6 & \\
\hline
\end{tabular}

2.G058036 can be used as a prognostic biomarker for patients with non-small cell lung cancer

The prognostic value of G058036 was assessed by Caplan-Meyer survival analysis.We found that OS
(Fig.2, $P<0.0001$ ) in the high expression group of G058036 were significantly lower than those in the low expression group, suggesting that increased expression of G058036 may predict poor prognosis of the disease. 


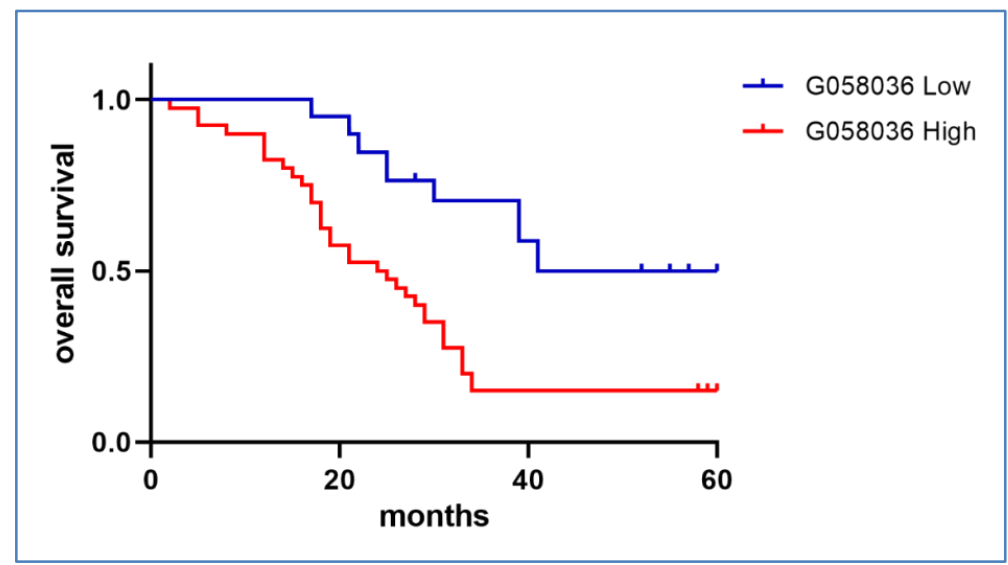

Fig-2: G058036 can predict the prognosis of patients with non-small cell lung cancer. Comparison of the overall survival (OS) rate between the high expression group and the low expression group of G058036 $(p<0.0001)$

3.3 Knockout of G058036 can inhibit the survival, proliferation, invasion and apoptosis of A549 and H838 cells
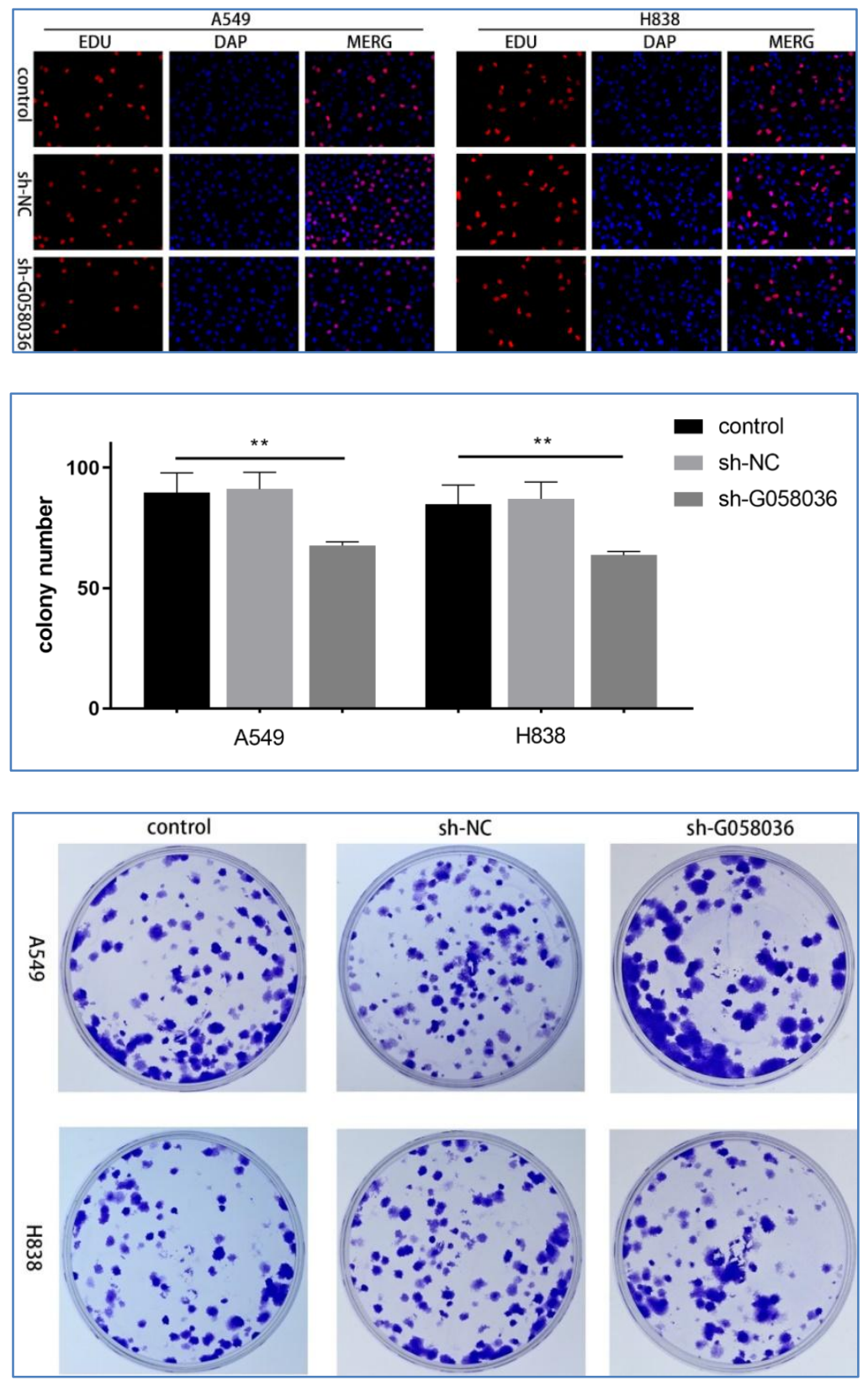

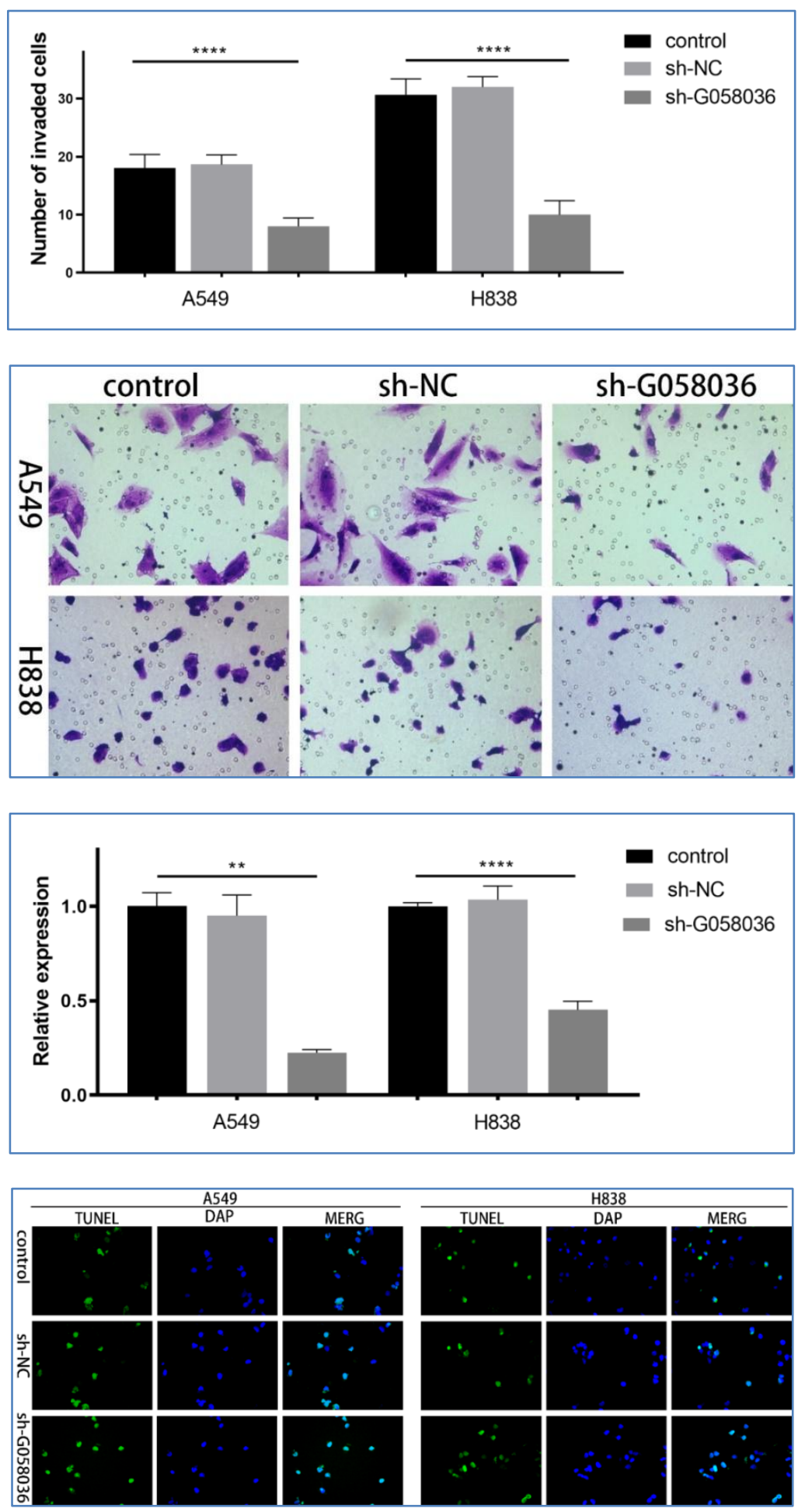

Fig-3.(a) The effect of sh-G058036 on the expression of G05036 in A549 and $\mathrm{H838}$ cells was measured by qPCR method (b) The effect of sh-G058036 on the proliferation of A549 and $\mathrm{H838}$ cells in vitro was observed by transwell experiment. (c) Observe the effect of sh-G058036 on the colony forming ability of A549 and $\mathrm{H838}$ through the clone formation experiment. (d) Observe the effect of sh-G058036 on the proliferation of A549 and H838 cells cultured in vitro by EDU experiment. (e) Observe the effect of sh-G058036 on A549 and $\mathrm{H838}$ cell apoptosis by TUNEL experiment.

$*_{p}<0.05, * * p<0.01, * * * p<0.001, * * * * p<0.0001$. Scale bar: 200 microns.

To further observe the biological function of LncRNAG058036 in non-small cell lung cancer, A549 and H838 cells were transfected with sh-G058036 and sh-NC, and the expression of G058036 in sh-RNA treated A549 and H838 cells was measured (Fig. 3A). In addition, transwell (Fig. 3B), clone formation (Fig. 3C), The experimental results of EDU (fig. 3D) and TUNEL (fig. 3E) showed that sh-G058036 could 
significantly inhibit the survival, proliferation, invasion and apoptosis of A549 and H838 cells.

\section{DISSICUSION}

In recent years, the incidence and mortality of NSCLC have been increasing year by year, which has posed a great threat to human public health [8]. Although there have been some achievements and advances in cancer research and treatment, the prognosis of various cancers, including non-small cell lung cancer, remains poor and the main cause of death among patients is tumor invasion and metastasis $[9,10]$.

At present, the five-year survival rate for lung cancer patients is less than $15 \%$, and the main cause of death for lung cancer patients is tumor invasion and metastasi [11]. Tumor metastasis is a multistep process. The process of tumor metastasis mainly occurs in epithelial-mesenchymal transformation (EMT) and epithelial-mesenchymal transformation (MET) [12]. EMT process is an important cause of metastasis of lung cancer [13]. EMT can enhance the invasions and metastasis of lung cancer by changing the characteristics of lung cancer cells and the microenvironment of cell survival [14]. The role of EMT in lung cancer metastasis has been widely studied, however, MET in lung cancer metastasis has been less studied .EMT and MET, as a continuous process, occur at different stages of metastasis during tumor metastasis [15]. Recent studies have shown that a small number of lncRNAs play an important role in EMT regulation and tumor invasion and metastasis, for example, long noncoding RNA-MALAT1 can participate in the EMT process of lung cancer cells by inhibiting the expression of polycomb protein SUZ12 [16]. Gas5-as1 can significantly promote EMT and lymph node metastasis of non-small cell lung cancer. Methyltransferase inhibitors could not regulate the expression of GAS5AS1, while histone modification inhibitors could significantly inhibit its expression [17]. $\mathrm{Xu}$ et al. reported that LncRNA MIR22HG was down-regulated in colorectal cancer (CRC) tissues and cells compared with normal tissues and cells [18]. Functional analysis showed that MIR22HG mediated Smad2/4-SNAI1 axis played a key role in the progression of colorectal cancer by regulating the EMT signaling pathway, and overexpression of MIR22HG inhibited the EMT process, thereby inhibiting the proliferation, migration and invasion of colorectal cancer [19].

Several recent studies on LnRNA in NSCLC have shown that they can promote the metastasis of NSCLC. For example, Wang et al. studied LINC00461, a newly identified lncRNA, which was significantly upregulated in NSCLC tissues and cell lines. In addition, knockout LINC00461 inhibits proliferation and invasion of NSCLC cells in vitro and tumor growth and metastasis in vivo, and further detects that LINC00461, as the LINC00461/ Mir-518a-3P /WDR1 axis, plays an important role in NSCLC [20]. Feng et al. [21] found that lncRNA DDX11-AS1 was highly expressed. Functional studies showed that DDX11-AS1 knockdown could significantly inhibit cell proliferation and induce cell apoptosis. Silencing DDX11-AS1 can inhibit p-Akt expression, and overexpression can increase protein expression. The results showed that DDX11-AS1 could regulate the progression of NSCLC by activating the PI3K/AKT signaling pathway. LncRNA TBX5-AS1 is down-regulated in non-small cell lung cancer tissues, and is related to lymph node metastasis and histological grade. Overexpression of TBX5-AS1 inhibits cell migration, invasion and apoptosis. In addition, tbX5-AS1 overexpression can inhibit the phosphorylation of $\mathrm{P} 13 \mathrm{~K}$ and AKT, inactivating the P13K/AKT pathway to inhibit the invasive phenotype of NSCLC [22]. After interfering with the expression of IncrRNAFBXL19-AS1, NSCLC cell proliferation was reduced, migration and invasion were weakened, cell cycle was stagnated at G0/G1 phase, and the expression of emT-related molecular markers (E-cadherin, N-cadherin, etc.) was changed [23].

\section{CONCLUSION}

In this study, we screened and analyzed LncRNA G058036, and conducted a study on the clinicopathological features and cell model experiments of NSCLC, and found that knockout of its expression could inhibit the metastasis, invasion and apoptosis of NSCLC. We only have a rough understanding of the function of LncRNAG058036 in NSCLC, but the specific direct mechanism remains to be explored and studied, so as to provide new ideas for the pathogenesis and treatment prognosis of NSCLC.

\section{ACKNOWLEDGEMENTS}

The present study was supported by the National Natural Science Foundation of China (Grant No. 81860500 and 81860523), the Natural Science Foundation of Guangxi (Grant no.2018GXNSFAA138009) and Guangxi Practical Health Technology Development and Promotion Projects (Grant S201674).

\section{REFERENCES}

1. Hirsch FR, Suda K, Wiens J, Bunn PA Jr. New and emerging targeted treatments in advanced nonsmall-cell lung cancer. Lancet. 2016;388(10048):1012-24.

2. Hiley CT, Le Quesne J, Santis G, Sharpe R, de Castro DG, Middleton G, Swanton C. Challenges in molecular testing in non-small-cell lung cancer patients with advanced disease. Lancet. 2016; 388(10048):1002-11.

3. Deel A. Nivolumab in Metastatic Non-Small Cell Lung Cancer. J AdvPractOncol. 2016;7(2):220-5.

4. Hirsch FR, Scagliotti GV, Mulshine JL, Kwon R, Curran WJ Jr, Wu YL, Paz-Ares L. Lung cancer: current therapies and new targeted treatments. Lancet. 2017;389(10066):299-311. 
5. Mercer TR, Mattick JS. Structure and function of long noncoding RNAs in epigenetic regulation. Nat StructMol Biol. 2013;20(3):300-7.

6. Xiao H, Tang K, Liu P, Chen K, Hu J, Zeng J, Xiao W, Yu G, Yao W, Zhou H, Li H, Pan Y, Li A, Ye Z, Wang J, Xu H, Huang Q. LncRNA MALAT1 functions as a competing endogenous RNA to regulate ZEB2 expression by sponging miR-200s in clear cell kidney carcinoma. Oncotarget. 2015;6(35):38005-15.

7. Evans JR, Feng FY, Chinnaiyan AM. The bright side of dark matter: lncRNAs in cancer. J Clin Invest. 2016;126(8):2775-82.

8. Siegel RL, Miller KD, Jemal A. Cancer Statistics, 2017. CA Cancer J Clin. 2017;67(1):7-30.

9. Peller PJ. Multiple myeloma. PET Clin. 2015;10(2):227-41.

10. Tang J, Chen JX, Chen L, Tang JY, Cui Z, Liu CH, Wang Z. Metastasis associated in colon cancer 1 (MACC1) promotes growth and metastasis processes of colon cancer cells. Eur Rev Med Pharmacol Sci. 2016;20(13):2825-34.

11. Perlikos F, Harrington KJ, Syrigos KN. Key molecular mechanisms in lung cancer invasion and metastasis: a comprehensive review. Crit Rev OncolHematol. 2013;87(1):1-11.

12. Nieto MA, Huang RY, Jackson RA, Thiery JP. EMT: 2016. Cell. 2016;166(1):21-45.

13. Tulchinsky E, Demidov O, Kriajevska M, Barlev NA, Imyanitov E. EMT: A mechanism for escape from EGFR-targeted therapy in lung cancer. BiochimBiophysActa Rev Cancer. 2019;1871(1):29-39.

14. Scanlon CS, Van Tubergen EA, Inglehart RC, D'Silva NJ. Biomarkers of epithelial-mesenchymal transition in squamous cell carcinoma. J Dent Res. 2013;92(2):114-21.

15. Yoshida T, Ozawa Y, Kimura T, Sato Y, Kuznetsov G, Xu S, Uesugi M, Agoulnik S, Taylor N, Funahashi Y, Matsui J. Eribulinmesilate suppresses experimental metastasis of breast cancer cells by reversing phenotype from epithelialmesenchymal transition (EMT) to mesenchymalepithelial transition (MET) states. $\mathrm{Br} \mathrm{J}$ Cancer. 2014;110(6):1497-505.

16. Fan Y, Shen B, Tan M, Mu X, Qin Y, Zhang F, Liu Y. TGF- $\beta$-induced upregulation of malat1 promotes bladder cancer metastasis by associating with suz12. Clin Cancer Res. 2014;20(6):1531-41.

17. Wu Y, Lyu H, Liu H, Shi X, Song Y, Liu B. Downregulation of the long noncoding RNA GAS5-AS1 contributes to tumor metastasis in nonsmall cell lung cancer. Sci Rep. 2016; 6:31093.

18. Xu J, Shao T, Song M, Xie Y, Zhou J, Yin J, Ding $\mathrm{N}$, Zou H, Li Y, Zhang J. MIR22HG acts as a tumor suppressor via TGF $\beta / \mathrm{SMAD}$ signaling and facilitates immunotherapy in colorectal cancer. Mol Cancer. 2020;19(1):51.

19. Zhang L, Li C, Su X. Emerging impact of the long noncoding RNA MIR22HG on proliferation and apoptosis in multiple human cancers. J ExpClin Cancer Res.2020;39(1):271.

20. Wang Z, Lu Y, Sheng B, Ding Y, Cheng X. Longnoncoding RNA LINC00461 promotesproliferation and invasion of nonsmall cell lung cancer cells via targetingmiR-518a-3p/WDR1 pathway. J Recept Signal Transduct Res. 2020:1-8.

21. Feng X, Yang S, Zhou S, Deng S, Xie Y. Long non-coding RNA DDX11-AS1 promotes non-small cell lung cancer development via regulating PI3K/AKT signalling. ClinExpPharmacol Physiol 2020;47(9):1622-1631.

22. Qu QH, Jiang SZ, Li XY. LncRNA TBX5-AS1 Regulates the Tumor Progression through the PI3K/AKT Pathway in Non-Small Cell Lung Cancer. Onco Targets Ther. 2020; 13:7949-7961. 32884287; PMCID: PMC7431607.

23. Yu DJ, Li YH, Zhong M. LncRNA FBXL19-AS1 promotes proliferation and metastasis via regulating epithelial-mesenchymal transition in non-small cell lung cancer. Eur Rev Med Pharmacol Sci. 2019;23(11):4800-4806. 